\title{
TRATAMENTO ASILAR, O DESAMPARO E O ACOMPANHAMENTO TERAPÊUTICO (AT)
}

\author{
TRATAMIENTO ASILAR, ABANDONO \\ Y SEGUIMIENTO TERAPÉUTICO (AT) \\ ASTLAR TREATMENT, HELPLESSNESS \\ AND THERAPEUTIC ACCOMPANIMENT (AT)
}

Ricardo Pimentel Méllo ${ }^{1}$

${ }^{1}$ Universidade Federal do Ceará, Fortaleza/CE, Brasil

RESUMO: Trata-se de texto ensaístico que, tendo como fundamento o conceito de desamparo, critica tratamentos asilares e conclui enfatizando a importância de não nos deixarmos capturar por propostas encarceradoras. As reflexões envolvem dois tipos de argumentações: (a) argumentos de conjuntura ampla relacionados a volta do movimento asilar associado ao uso compulsivo de drogas e de políticas de abstinência; (b) argumentos relacionados a conjuntura micropolítica que nos afeta por advirem de nossa luta antimanicomial e da ética antiproibicionista. Tais conjunturas se congregam, nos impulsionando para que não recuemos diante dos quadros de violência extrema que se apresentam onde atuamos e sejamos politicamente criativos. O Acompanhamento Terapêutico pode ser essa vigorosa arte-clínica, alinhada à extinção de tratamentos asilares, se entende que nosso desamparo primordial nos funda em laços com humanos e não humanos e, em oposição aos manicomicidas (assassinos do desejo), não tratando como doentes aqueles que destoam em suas formas de viver.

PALAVRAS-CHAVE: Tratamento asilar; Acompanhamento terapêutico; Desamparo; Luta Antimanicomial.

RESUMEN: Se trata de un ensayo que, a partir del concepto de desamparo, critica los tratamientos de asilo y concluye enfatizando la importancia de no dejarnos atrapar por propuestas de encarcelamiento. Las reflexiones involucran dos tipos de argumentos: (a) argumentos de amplio alcance relacionados con el retorno del movimiento asilar asociado al uso compulsivo de drogas y de políticas de abstinencia; (b) argumentos relacionados con la situación micropolítica que nos afecta ya que surgen de nuestra lucha anti-manicomio y ética antiprohibicionista. Esas situaciones se juntan, urgiéndonos a no retroceder ante la violencia extrema que se presenta en todos los lugares donde operamos y a ser políticamente creativos. El Acompañamiento Terapéutico puede ser este vigoroso arte-clínico, alineado con la extinción de los tratamientos de asilo, se entiende que nuestro desamparo primordial nos funda en lazos con humanos y no humanos y, en oposición a los manicomicidas (asesinos del deseo), no tratan como enfermos a aquellos que desatan en sus formas de vivir.

PALABRAS CLAVE: Tratamiento asilar; Acompañamiento terapéutico; Desamparo; Lucha anti-manicomio.

ABSTRACT: This essay is based on the concept of helplessness, it criticizes asylum treatments, and concludes by emphasizing the importance of not allowing ourselves to be captured by incarceration proposals. The reflections involve two types of arguments: (a) wide-ranging arguments related to the return of the asylum movement associated with compulsive use of drugs and abstinence policies; (b) arguments related to the micropolitical situation that affects us as they arise from our anti-asylum struggle and anti-prohibitionist ethics. Such situations come together, urging us not to retreat from the extreme violence that presents itself wherever we operate and to be politically creative. Therapeutic Accompaniment can be this vigorous clinical art, aligned with the extinction of asylum treatments, if we understand that our primordial helplessness is based on ties with human and non-human ties and, in opposition to manicomicides (murderers of desire), we do not treat as sick those who differ from the majority because of their ways of living.

KEYWORDS: Asylum treatment; Therapeutic accompaniment; Helplessness; Anti-asylum movement. 
Trabalho, tormento, desgosto e miséria tal é sem dúvida durante a vida inteira o quinhão de quase todos... Mas se todos os desejos, apenas formados, fossem imediatamente realizados, com que se preencheria a vida humana, em que se empregaria o tempo? (Schopenhauer, 1850/2014, pp. 26-27)

Propomos, neste texto, uma reflexão teórica que visa a contribuir com argumentos técnico-acadêmicos contrários a quaisquer ações que se nomeiem de "tratamento" ou de "cuidado em saúde", baseadas no encarceramento. Há, portanto, alinhamento com a extinção de tratamentos asilares, nos quais as formas de proceder atingem, de maneira discriminatória e violenta, empobrecidos e negros, e são justificadas em argumentos que casam anormalidade com periculosidade, desenvolvemos Tal postura sustenta o trabalho desenvolvido no "Núcleo de Estudos sobre Drogas" (NUCED), com ações de Redução de Danos (RD), as quais já ocorrem desde 2004, e também com trabalho de "Clínica Nômade" ou "Acompanhamento Terapêutico" (AT), iniciado em 2017, no Departamento de Psicologia da, na Universidade Federal do Ceará.

Todos os que estamos desenvolvendo algum trabalho, nas periferias das capitais brasileiras, vivemos um momento dificílimo, o qual nos coloca em risco, ao sairmos errantes em algumas áreas. Eis que um duplo enclausuramento se ergue diante de nós, querendo nos capturar: a proposta de tratamentos asilares e as dificuldades para a nossa circulação. O desamparo das pessoas a quem direcionamos nossas ações e o nosso próprio desamparo tentam nos enrijecer e nos tornar aliados do medo, que impede a vida de fluir nômade. Somos tentados a nos asilar e, novamente, evitar o trabalho junto à população empobrecida, a quem deveríamos nos dedicar, caindo na mesma esparrela de ampliar o estigma de que essa população é perigosa. Essa situação exige ainda mais criatividade e arte, na clínica. Assim, o desamparo criativo, face a situações de dores e perdas deveria nos levar ao trabalho de luto relacionado, envolvendo um processo de criação (Vieira \& Cintra, 2016).

Vemos perplexos o movimento asilar reavivado e crescendo no Brasil, por meio de propostas governamentais, oficializando a fracassada política de abstinência, sob a alegação de tratar a compulsão ao uso de substâncias psicoativas. Retoma-se a solução simplista de clausura e privação. Em si, o uso compulsivo de substâncias já tem complexidades as quais nos remetem para além de uma análise nosográfica e metapsicológica, sem excluí-las, porque nos impele a pensar os modos de viver contemporâneos transdisciplinarmente, questionando os nossos limites teóricos, para ampliá-los. Em contraposição à clausura, o princípio da liberdade é intocável, pois, sem ele, não há arte na clínica ou na vida.

Liberdade é exercício de invenção de si mesmo para que não se viva sob a sujeição de modos de produção vital heteropatriarcal, colonial e neonacionalista "que visa desfazer as conquistas de longos processos de emancipação operária, sexual e anticolonial dos últimos séculos" (Preciado, 2018, p. 11). Assim a liberdade se exerce com autonomia, para que não impere a coerção, permitindo sermos uma máquina de experimentações de modos de viver não neofascistas. O desejo deve ser remetido ao campo das disputas políticas que opõem, de um lado, "política fascista, paranoica, capitalista, burguesa, reterritorializadora” (Deleuze, 2018, p. 208), e de outro, política de abertura do desejo a conexões com a vida fluida, solidária e libertária. De maneira ainda mais detida Foucault nos mostrou como o poder nos subordina a certas maneiras de viver, como condição para que que nos tornemos humanos. Politicas fascistas/autoritárias e políticas de abertura/criativas estão em disputa nos constituindo. A subordinação nos produz como humanos, mas precisamos 
ter capacidade de resistir, insubordinar, em última instância contra esse "eu" fundador. Capacidade esta de negar nossa formação inicial na dependência (Butler, 2017). As chamadas "técnicas de si" que remetem ao "cuidado de si", no contemporâneo, são alvos de controle da "governamentalidade", ou seja, assim como nos constituímos como sujeitos em relações conosco mesmo (relações consigo), nos dobrando, nos constituindo como sujeitos em determinados modos de viver, tais modos de viver são estratégicos no controle de cada um de nós em relações de poder, nos sujeitando a uma certa prática ou certa forma de governo chamada por Foucault (1997) de "governamentalidade". Nos enredamos nas malhas de certo viver, em certos agenciamentos, "numa intricada relação de regimes de verdade que nos impõem irmos atrás de confessarmos quem somos: dizer a verdade sobre nós mesmos” (Méllo, 2019, p. 232). Nós fazemos em agenciamentos diversos, múltiplos, híbridos, estruturados "por uma racionalidade prática e governado por um objetivo mais ou menos consciente" (Méllo, 2018, p. 126).

Nossa clínica é política na medida em que entendemos o sujeito formado em relações de poder que sempre põe algo em ato: ora nos subordinamos ao que nos formou, ora desejos de mudança se fazem em nós em insubordinação criativa. Nossa clínica deve acompanhar os movimentos que criam a vida e constituir-se também em arte. Entendemos arte como o criar "um finito que restitua o infinito" (Deleuze \& Guattari, 1992, p. 233). Portanto, qualquer composição que crie um plano imanente a uma obra (artística), efetuando sensações, sem preocupação com representacionismos que desejem retratar com fidelidade o "real", mas buscando expor sensações que nos atinjam: "a filosofia faz surgir acontecimentos com seus conceitos, a arte ergue monumentos com suas sensações, a ciência constrói estados de coisas com suas funções” (Deleuze \& Guattari, 1992, p. 255). Trata-se de uma "lógica dos sentidos", a qual deve propor um devir outro, sustentado em diferenças ou, como afirma Justo: ir além do "papel cristalizador de um sujeito hominizado e 'humanizado', constituído de modo estável e auto-reiterado, para inversamente aceitar as múltiplas formas de transformação que a sensação desencadeia” (Justo, 2001, p. 17, citado por Farina, 2015, p. 47). A arte se faz pelo seu efeito de criar e proporcionar - tanto para quem a inventa, quanto para quem se depara com ela - experiências inusitadas, para além das sensações a que estaríamos habituados (Pessoa, 1988, p. 176). Portanto, a arte-clínica não comporta encarceramentos, porque estes nos prendem no habitual, na identidade, no territorializado ad eternum.

Quanto ao desejo, é entendido como devir, ou seja, não como impulso favorecido por algo que nos falta e condenado a repetição, mas como "pulsão vital” (Rolnik, 2018), que se faz em nossos modos de viver ou modos de subjetivação, em processos "produzindo efeito de sujeito transitório, não por ser incompleto, mas por ser criativo” (p. 424). Desejo, como conceito, deve ser articulado com liberdade, com a invenção de formas de vida criativas que nascem das redes de agenciamentos constituídas por humanos e não humanos.

Partimos da premissa de cuidado em liberdade e autonomia, associando-o a argumentação psicanalítica de que o ser humano se funda em situação de desamparo (Freud, 1926/1992), que sempre retorna sob a forma de algum "mal-estar". Como confirma Rocha (1999), essa articulação conceitual foi feita por Freud desde o momento em que se referiu às feridas narcísicas impingidas ao ser humano: (a) a terra não é o centro do universo (Copérnico); (b) fazemos parte do mesmo reino animal que outros seres (Darwin); (c) a razão nos engana e “o eu não é mestre em sua própria casa” (Freud, 1917/1976, p. 175). 
Tal desamparo deve ser entendido menos como uma fragilidade, ainda que a contenha, e mais como uma abertura à inovação, à invenção de modos de vida, portanto, como uma resistência à mesmice e repetições do viver. Assim, tragicamente, sempre convivemos com a potência da dor e a potência do desamparo. O que impera, por conseguinte, não é a inércia, diante da fragilidade de nossas proteções, mas a direção à realização de algo ou, como nos ensinou Nietzsche (2008), de fazer a vida acontecer num movimento de devires. Nesse caso, proteção na dor e desamparo não se referem a uma redoma feita de vidro blindado, a qual nos protegeria e impediria ou, ainda, anteciparia algo que nos faria sofrer, muito menos evitaria o desamparo que nos constitui. O nosso desamparo inicial ${ }^{1}$ fomentou a nossa arte de nos tornarmos humanos, impulsionando-nos a estabelecer conexões com humanos ou não humanos, conexões com nossos primeiros objetos amorosos (nossos cuidadores), bem como com substâncias e objetos que nos proporcionaram sensações as mais diversas e que despertaram nossa atenção, cheiros, sons, gostos, luzes etc.

Ora, se nós nos constituímos e vivemos em laços sociais, provocados pelo desamparo, é importante perguntar: que laços se fazem, no enclausuramento/isolamento? Quando alguém adoece, um tratamento intensivo pode ser fundamental, para que a vida não seja interrompida e siga fluindo, mesmo se o adoecimento pedir internamento passageiro. Portanto, internar, em si, não comporta um problema. Todavia, as suas conexões podem nos indicar se vão em direção à fluidez da vida ou em direção oposta, fomentando isolamento por preconceito e/ou higienismo exterminador. É isso o que temos visto com a inclusão de lugares de internação à rede de saúde, que se autodenominam "comunidades" e ainda colam a esse termo o adjetivo de "terapêuticas" (Galindo, Moura, \& Méllo, 2017). E por quê? Porque não é uma proposta que se sustente em bases teórico-metodológicas, as quais compreendam nossos desamparos, nossas feridas narcísicas, nossas melancolias e nossos mal-estares como potências. Tratam dores e desamparos como pontos fora da curva do que supõem ser normal e pregam a ilusão da felicidade duradoura (Méllo, 2016). Querem isolar e afastar a dor como potência da vida societária. Nesse raciocínio, quem expõe suas dores deve ser recolhido, enclausurado, isolado, pois sua semiótica não interessa a quem já padronizou uma. E mais, quem enclausura é contra o prazer que não venha de suas regras controladoras: prazer só o regulado pelos princípios dos encarceradores do prazer que vaga sem as suas regras.

Nós nos constituímos como humanos, no desejo do outro que está cuidando de nós. O outro, inicialmente, fala e sente "por nós" e vai nos ajudar a colocar isso em modos de comunicação, tais como gestos e palavras. Temos dependência em relação a um outro que nos alimentará, mas também esse outro desejará "por nós" e formará nossos desejos no mundo da linguagem, tornando-nos humanos. Assim considerado, o desamparo é constituinte da inserção do sujeito no mundo da linguagem:

A Hilflosigkeit [desamparo] freudiana refere-se, primeiramente, ao estado em que se encontra o recém-nascido, completamente impossibilitado de poder ajudar-se a si mesmo com seus próprios recursos. De fato, dificilmente se poderia imaginar um estado de desamparo maior do que esse do recém-nascido, o qual, por causa de sua imaturidade motora e psíquica, é ... alguém totalmente incapaz de satisfazer sozinho às suas necessidades vitais de sobrevivência. (Rocha, 1999, p. 334) 
Aprendemos com a virada linguística que nenhuma linguagem conseguirá representar o mundo, porém, inventá-lo, mudando de tempos em tempos o que se considera verdadeiro. Assim, nossas angústias e medos advêm dessa nossa formação originária que nos tornou "máquinas desejantes" (Deleuze \& Guattari, 1976), criadoras de modos de viver. Inspirado em Almodóvar (2011), podemos afirmar que a pele que habitamos são os modos que construímos para viver. Parece fácil, contudo, não é, pois a pele que habitamos muda constantemente com a vida que habitamos, já que sempre a inventamos. Os humanos mudam a pele de forma contínua: mudamos continuamente nossos modos de viver. Mudanças geram os mais diversos sintomas, porque unem dores e alegrias, e tanto uma como a outra têm efeitos múltiplos em nós.

Os anti-SUS e anti-SUAS, anti-Reforma Psiquiátrica, os que não querem "mudanças de pele", os obstinados em prender e isolar para tratar, são os que propõem uma espécie de intervenção militar no desejo, porque só veem saídas em ações de guerra como a prisão, internação compulsória e uso da força. Não percebem que nosso desamparo primordial nos funda no desejo do outro, portanto, nos torna humanos, em laços com humanos e não humanos. Ao contrário, os manicomicidas (assassinos do desejo) intensificam o desamparo, sem cuidar dele. Fazem os "seus internos/enclausurados" se reconhecerem como desamparados — como se todos nós não fôssemos assim — e, ao procederem dessa forma, cunham o desamparo como uma anormalidade. Os tratamentos carcerários se aliam à doença e vivem dela, seja para lucrarem com internações remuneradas, seja para apaziguar consciências e reforçar virtuosidades, em internações piedosas e filantrópicas. Para o desamparo que pode potencializar vida, oferecem desamparo que potencializa a morte, e dissimulam as causas propulsoras da dor. Agindo assim, é como se o desamparo estivesse desligado do desejo que o produz e se ligasse só às angústias expressas em sintomas.

A Psicanálise foi a responsável pelo atrelamento do desamparo-desejo-inconsciente, advogando a fundação do humano nessa tríade inseparável. O desejo é central na constituição do humano e na manutenção da nossa ilusão de sermos uma espécie. Bem sabemos que não há consenso sobre o conceito de desejo, o qual tem, pelo menos, quatro vertentes: a do próprio Freud, a de Girard, a de Lacan e, por fim, a de Deleuze e Guattari (Lacan, 1985; Santos, 1997). Já, abordamos brevemente sobre a concepção de desejo com a qual nos identificamos nesse texto. Passaremos a discorrer um pouco mais sobre esse tema, para, a seguir, finalizar o raciocínio remetendo o texto ao trabalho do AT.

Com Deleuze e Guattari, o desejo passa a ser pensado como produção. Discorrem sobre o desejo em uma matriz que o alia à produção e criatividade. Dessa feita, podemos raciocinar que fomos sendo produzidos como espécie humana, a partir do desamparo, o qual, ao invés de nos colocar em uma posição inerte, produziu laços que foram nos constituindo e nos fazendo afirmativamente. Aprendemos a nos produzir e terminamos por não caber em identidade (pele) alguma que nos faça inerte, ou que nos queira selar como idênticos: louco, maconheiro, viciado, psicólogo, professor, homem etc.

Repetindo, nós vivemos o desejo do outro e nele nos formamos. Tal formação inicial nos acompanhará para sempre por ter sido estruturante. Permanecermos no desejo do outro, que assim nos estruturou, gera angústia, seja porque esse desejo nos engole, seja porque não é fácil nos separarmos desse desejo, em busca de outros laços que também são incertos. Separações, desejadas ou não, geram alguma aflição (tais como separações amorosas ou mortes). Ao mesmo tempo, só o desejo do outro, em nós reconhecido, nos potencializa, porque nos sentimos aceitos e partícipes de uma rede relacional. 
Ora, o que fazem os tratamentos carcerários? Impedem a circulação de alguém, limitam a sua potencialização, propõem um cotidiano restrito a dor e a algum sintoma, o qual, por ser colocado em relevo, esconde e sabota possibilidades de fazer emergir as suas causas. "Tratam" o desamparo de quem inter nam impedindo o desejo mobilizador que potencialize o "cuidado de si", atendo-se aos sintomas ${ }^{2}$ estes entendidos, de forma ampla, como certo arranjo feito por uma pessoa, que funciona como uma defesa para manter fora de sua consciência lembranças/vivências traumáticas (Maia, Medeiros, \& Fontes, 2012). Essa forma de agir tem efeitos que dissimulam as causas propulsoras da dor, camuflando-a: comemoram o fato de o internado deixar, temporariamente, o uso de certa droga, por exemplo. Por isso, somos reticentes quanto aos tratamentos carcerários, mesmo naqueles estabelecimentos nos quais os muros são camuflados de verdejantes trepadeiras. Como não têm sustentação teórica que não a boa vontade ou a avidez financeira, tratam sintomas, querendo apenas derrubá-los, impedi-los de se manifestarem. O que ocorrerá? (a) Apenas uma troca de sintoma - considerado como vitória; (b) O abandono do tratamento (sempre concebido como fraqueza de quem não se rende a certa terapêutica que, em si, é falseadora). Pesquisas indicam taxas de desistência do tratamento que variam de 30\% a $70 \%$, quer em adolescentes, quer em adultos, especialmente quando o foco está no uso de álcool (Almeida, 2013; Fernandes, Marcos, Kaszubowski, Goulart, 2017). Diferentemente da proposta carcerária, acompanhamos as perspectivas que propõem que o sintoma não seja foco, especialmente por ser um anteparo que protege de uma dor maior e, como tal, é relevante para a vida de alguém e o faz manter-se vivo.

O Acompanhamento Terapêutico é importante como proposta político-clínica não asilar, desde que não faça dos espaços apenas caminhos e paisagens para mobilidade e circulação. Não basta sair às ruas com "pacientes”, usando uma cidade sem movimento, tendo o território como paisagens, pano de fundo, sem que neles se adentre. Os lugares por onde o AT transita com seu acompanhado - usando uma imagem de Virilio (1993) - funcionam tal como pontos (pixels), os quais, juntos em rede narrativa, compõem imagens que exercitam a vida na reinvenção de paisagens. Tais pontos que compõem certo cenário de vida, que se mobilizam na potência do desamparo, podem ser pensados como linhas de fuga à mesmice da dor. Assim, o trabalho do AT tem como principal potência atentar aos pontos de fuga capazes de mobilizar o acompanhado para além de certo aprisionamento de modos de viver repetitivos e adoecedores. O deslocamento pelas ruas, ativa lembranças que podem ser manejadas em escuta no sentido de favorecer a fluidez da vida. Por exemplo: certo Acompanhamento que iniciamos, foi com um senhor diagnosticado com demência por uso de álcool. Sua família e médicos o tratavam como um "imprestável”. Certa vez, relatou que sentia saudades do interior onde nascera por ter bichos e muitas árvores. Seu Acompanhamento seguinte foi no zoológico da cidade e teve desenrolar potente: lá expressou-se intensamente por meio de palavras e gestos (como nunca acontecera), pondo-se a relembrar aspecto significativos de sua vida, importantes para seu cuidado em saúde, especialmente, vitalizando a possibilidade de retomar laços sociais, rompendo com o subjetivar-se cíclico como inútil.

Palombini (2007) nos brindou com a imagem do flâneur de Benjamin: o acompanhante terapêutico seria esse flâneur, que facilita a vivência da dor e aponta para o desejo que maquina transformá-la em potência de vida. Dessa forma, o AT, como técnica terapêutica, seria esse flâneur que facilita a reinvenção de paisagens, na efemeridade do tempo-espaço contemporâneo. O espaço volta a ser público, abrindo-se para uma singular 
“micronarrativa” (Virilio, 1993), a qual se articula às narrativas do território, produzindo no acompanhado um sentimento de pertença, em contraposição a certa vivência de sentir-se excluído. O acompanhante terapêutico convida o acompanhado a imergir em pontos de fuga que favorecem conexões para sua vida fluir em passagens por outros territórios vitais. Do mesmo modo, como proposta político-clínica, o AT se funda na liberdade e convida todo o campo da saúde a resistir aos assassinos do desejo que nos querem desamparados, à mercê de processos de captura de nossa potência criativa.

Ora, a reclusão/enclausuramento propõe o inverso: a preponderância das metanarrativas sanitaristas e preconceituosas, as quais, com seus muros, se aliam às políticas higienistas que excluem a micropolítica singular, excluem o acompanhado do território, da circulação e da vida comum. Daí que os lugares de "tratamento", clinicas de reclusão-exclusão, precisam ter o nome de "comunidades", para serem lembradas como tal, em um golpe de marketing, querendo o efeito de nos fazer esquecer que são o inverso disso, por se constituírem na exclusão e na hierarquização: espaços de vigilância e controle da micronarrativa e dos laços sociais.

Certamente, o adjetivo “terapêutico” também merece uma reflexão. Foucault, esclarece:

'therapeúein', que é um verbo de múltiplos valores: therapeúein refere-se aos cuidados médicos (uma espécie de terapia da alma de conhecida importância para os epicuristas), mas therapeúein é também o serviço que um servidor presta ao seu mestre; e, como sabemos, o verbo therapeúein reporta-se ainda ao serviço do culto, culto que se presta estatutária e regularmente a uma divindade ou a um poder divino. (Foucault, 1997, p. 10)

Terapêutico é um serviço de cuidado. No AT, a palavra é fundamental, se vaga como narrativa livre. Por livre se entenda sem restrições de qualquer ordem, inclusive sem restrições morais. Assim, durante o acompanhamento terapêutico, seria possível narrar episódios de consumo de substâncias ilegais, sem restrições morais. Narrar livremente é muito diferente de confessar por se sentir em dever de narrar. O maior ensinamento da psicanálise é o rigor na "associação livre”: o rigor da narrativa sem amarras confessionais, sem amarras prejulgadoras de um terapeuta-ouvinte (virtuoso), diante da narrativa de um "paciente-perdedor" (pecaminoso). Os efeitos terapêuticos do AT (como na psicanálise) se fundam na liberdade total de expressão: narrar tudo, mesmo que pareça ilógico ou amoral. Sem essa liberdade, não há AT.

O setting deve ser um espaço de liberdade. O divã é um símbolo disso, onde alguém pode se deitar e se despojar de tudo, menos da sua liberdade de narrar. O divã, como símbolo, acompanha o AT, sob a forma de um território. Para o AT, o espaço está sempre aberto para a criação de modos de vida, aberto ao acaso. O caso se faz no acaso. Falar do AT é se contrapor a procedimentos que aprisionam o desejo e que querem formatar o outro. O AT é um resistente: começa resistindo a uma formação, como no campo "psi”, no qual, geralmente, se propõe a reclusão na dor, sem potencializar a dor para que ela flua. Nesse caso, é como se o desamparo estivesse desligado do desejo que o produz e se ligasse somente às angústias expressas em sintomas: a narrativa só circundaria o sintoma, provocando raciocínios moralistas, sem provocar análise. 
No início do texto, vimos que as nossas angústias advêm das incertezas sobre nós (entrelaçados no mundo), que construímos e vivemos. Isso nos potencializa, quando se entrelaça para continuar criando com nossos modos de viver. E nos prende, quando o mundo espaço delimitado pelas normalidades sem invenções, ou seja, quando não exercitamos a arte de viver. A solução não é a completa renúncia às dores ou o seu aprisionamento por trás dos muros dos sintomas e dos tratamentos asilares, todavia, a afirmação da nossa condição de desamparo traz vida pelo seu enfrentamento. Essa postura decorre de pensadores contemporâneos de Freud, destacadamente Nietzsche, para quem a felicidade "não é conforto, bem-estar, ausência de conflito ou completa pacificação", mas o enfrentamento da intensidade das dores, mal-estares e angústias: "feliz é aquele que consegue viver tudo isso até as últimas consequências, sendo igualmente capaz de permitir que outros também vivam esta intensidade" (Giacóia, 2002, s/p).

Será que os acompanhantes terapêuticos estão seguindo essa linha de trabalho? AT parece estar virando moda: vemos essa modalidade clínica se espraiando pelo Brasil. Não nos espantemos, quando comunidades terapêuticas ou hospitais psiquiátricos desejarem contratar acompanhantes terapêuticos, para passearem com "seus pacientes" e exercerem a função de "distrai-dores”, usados para "trair-dores”, ao invés de seguirem fiéis a expor as dores. Esse distraidor passearia com pessoas, tal como se passeia com um animal de estimação. O nomadismo da clínica AT não é ir às ruas e seguir certo trajeto, porém, nele permitir deslocamentos, de si, do outro e do território.

A resistência do AT está em alguns princípios éticos de cuidado "que acolha o outro em seu desejo mais do que justo de prazer” (Méllo, 2018, p. 102). Seguimos Foucault, na ética do cuidado de si: o cuidado deve constituir-se como um "exercício de si" que permita uma "experiência modificadora de si no jogo da verdade" (Foucault, 1984, p. 13). Defendemos um retorno à ética cínica. Esse termo infelizmente foi deturpado na modernidade tardia, mas com ele desejamos nos referir à filosofia dos cínicos, anteriores ao cristianismo, a qual exige o falar franco e que se aproveitem os prazeres da vida, por meio da sua regulação, como no caso de uso compulsivo de substâncias. Nesse caso, a ética cínica é:

Reconhecer a potência dessa população de "drogados", como os que vivem nas ruas, é apostar na despatologização da vida livre. Transgridem de forma importante, como cínicos, onde testam limites do corpo, limites das condutas, limites do consumo, limites de riscos. Reconhecer essa potência e não apenas os classificar como portadores de "distúrbios mentais" ou acusá-los de estarem colocando à mostra estruturas perversas. Talvez haja mais perversidade em uma sala de aula nas relações entre professor e estudantes do que, à céu aberto, entre moradores de rua. Cuidado pressupõem reconhecer potencialidades: moradores de rua, nela demostram capacidades de resistências, nela se alegram e se entristecem, como cada um de todas e todos seres mortais. (Méllo, 2018, pp. 137-138)

Infelizmente, clínica se tornou sinônimo de consultório desenvolvido em uma sala. A té mesmo quando a clínica se faz nas ruas, acabou tendo o nome de consultório (“consultório na rua”). Contudo, podemos entender o trabalho clínico como mais amplo que uma consulta, e aqui entra o trabalho do AT como fundador de uma clínica nômade que retoma conceitos importantes, retirando o consultório do risco de um sedentarismo teórico-metodológico. Nesse caso, a clínica do AT se constitui como um espaço em mutação, o qual potencializa maneiras de viver, fazendo-se em territórios que traçam linhas 
em trajetos colocados em movimentos. Entendam-se trajetos como o movimento de união entre histórias de vida, laços sociais, acasos do momento presente vividos no território. Virilio (1993) nos fala do "trajetivo" como o movimento que está além da divisão binarista de objetivo e subjetivo, que, no caso do trabalho do AT, possibilitaria um certo regime de visibilidade dos trajetos, dos deslocamentos que alguém fez e faz, interligado extensivamente ao mundo, por meio do movimento em um território. Portanto, o nomadismo da clínica AT não é ir às ruas e seguir certo trajeto, mas nele permitir deslocamentos, de si, do outro e do território. Deve-se levar a sério que ninguém passa no mesmo lugar da mesma maneira. $\mathrm{O}$ mundo construído pelas tecnologias informáticas e imagéticas passou a ser pequeno e conhecido, porque aprisionado na mesmice, como se fosse possível “o esgotamento das distâncias e, portanto, da ameaça da inércia” (Virilio, 1993, p. 127). Esse é o risco de tornar o sujeito previamente conhecido como sendo o seu sintoma (alcóolatra, por exemplo), ou o território previamente conhecido como tendo certos prédios com certas funcionalidades e, literalmente, trancafiá-los nessa mesmice. Esse é o risco dos processos aprisionadores de identidades (sejam as de drogaditos, sejam as de terapeutas), as quais não mobilizam as potências mutantes do espaço clínico, inventando-o, criando-o como um artista, que só tem diante de si uma tela enfadonhamente branca.

Como em tudo em nossa vida humana, precisamos de algumas linhas que tracem territórios que possam nos iludir sobre os espaços que supomos familiares. No entanto, a familiaridade intensa leva ao tédio e à melancolia. Creio que o AT é essa vigorosa arte-clínica, a qual nos joga em direção ao incômodo, que, por sua vez, nos tira da inércia e nos propõe traçar outras linhas que nos iludam sobre nossos territórios, nesse efeito de vibrar em novas pulsações, novos modos de viver. Lembro-me aqui de Fernand Deligny (trabalhou na clínica La Borde, com Guattari e Jean Oury): preocupado com as ações que pudessem normalizar os chamados "anormais", um risco que pode também capturar os AT, em seu trabalho com crianças estigmatizadas como autistas, Deligny sugere traçar os mapas das errâncias dessas crianças:

Os mapas procuram nos dar imagens que não sejam aquelas do reconhecimento, imagens de um reflexo no espelho - ao contrário, eles buscam fabricar imagens onde não possamos nos reconhecer e a partir das quais possamos ver não o que falta às crianças, mas o que falta a nós. Trata-se, pois, de imagens furadas, onde a posição do sujeito que reconhece a si mesmo se desmorona, diferente, pois, de imagens-espelho, onde o sujeito se reconheceria e se confirmaria. Os mapas provocam dessa forma um deslocamento e uma mudança de perspectiva. As crianças são vistas como singulares e diferentes, mas isso não implica que haja uma diferença de grau ou de natureza em relação a elas. Os adultos "normais" não devem pois se projetar sobre elas, não devem "semelhantizar.” (Miguel, 2015, pp. 60-61)

Vale o alerta para o asilo que também podemos construir, em nossa prepotência teórico-metodológica, onde os muros de nossas teorias e métodos nos abrigam e nos impedem de nos entregarmos às linhas de fuga que o AT possa nos proporcionar. O asilo não é só reclusão espacial, mas é impedimento de retraçar linhas, pois quer que, a cada dia, o asilado seja um isolado. Já o retraçar linhas na clínica-arte sempre nos coloca como exilados, porém, em outro sentido: o de estar sempre em um território que deve ser desconhecido, para que possa ser recriado e, assim, a vida não ser encolhida pela mesmice melancólica. 
Nesse caso, viver exilado é saber que o paraíso está perdido e sem volta, mas também saber que não há nada que magicamente trace a vida, ao contrário, o indefinível da arte emociona e, nesse toque ou nesse encontro, há uma aposta do AT que desfaz e refaz linhas territoriais em busca de um traçar que emocione, que surpreenda. Fazendo um paralelo com o que Deleuze expõe sobre uma aula, a atividade de um AT "não é uma questão de entender e ouvir tudo", contudo, como em uma aula, "acordar em tempo de captar o que lhe convém pessoalmente." No AT, alguma coisa deve acontecer, a ponto de fazer acompanhante e acompanhado acordarem para alguma coisa que convém traçar como linha de fuga. No AT, algo deve surpreender e emocionar, de sorte a fazer o outro acordar para algo que convém traçar como linha de fuga. São trajetórias que fazem experimentações na fronteira estabelecida como vida vivida, para ir além dela, em busca de novas configurações. A emoção a que se referiu Deleuze é movimento, é força, e não um sentimento interno, guardado em uma suposta "mente".

As organizações asilares encarceram a experimentação, porque só repetem as fronteiras antes fixadas. Impedem que se desfaça certa pele cristalizada como modo de viver no mesmo. Portanto, cartograficamente, o AT busca "explorar o território e acompanhar algumas linhas que emergiram de cada um dos campos em direção aos outros. Essas linhas são obras, trajetórias e experimentações..." (Lima \& Pelbart, 2007, p. 711). Tais linhas, percursos, são construídos por agentes coletivos que dão movimento às nossas vidas, em nossos processos de subjetivação. As propostas asilares não se afinam com construções coletivas, pois se sustentam em proposta política segregacionista, em certa clínica apoiada em patologias e remissão de sintomas; apostam em estética feita de muros, grades e interioridades. Em contraposição, o nomadismo do AT antissegregacionista está apoiado na arte de criar vida, em espaços territoriais que a movimentam coletivamente; apostam em trocas sociais e não na indústria farmacêutica ou no empresariado que deseja lucrar com a dor alheia. Ou seja, o AT se inclui na mesma proposta do teatro da loucura, proposto por Peter Pál Pelbart, por construir uma "esquizocenia" (cena esquizoide) que funciona como dispositivos "multifacéticos - ao mesmo tempo políticos, estéticos, clínicos- na reinvenção das coordenadas de enunciação da vida" (Pelbart, 2013, p. 129).

Nossa aposta é que a vida pulsa mesmo em meio à dor, especialmente se é acontecida em arte, na ludicidade, se fazendo potência:

Maconha, cocaína, ayahuasca, analgésicos e antipsicóticos

Inalantes, Ecstasy, LSD e heroína

Álcool, café, chocolate e açúcar

"O pulso ainda pulsa. O pulso ainda pulsa..."

(O Pulso, Titãs) 


\section{Notas}

1 É importante nos referimos a Ferenczi (1929/1992) que reconhece certo desamparo que poderíamos dizer ontológicos, por serem constitutivos da vida humana (nascemos em estado de desamparo e dependência), mas, ampliando a visão freudiana, nos disse que o desamparo, por si, não é traumático, mas depende da relação do bebê/criança com seus cuidadores, enfatizando que, a presença de outros é decisiva no desenvolvimento humano, impondo uma perspectiva relacional ao desamparo. Winnicott (1975), seguirá nessa linha, reportando a importância de cuidados adequados ao bebê/criança, para uma vida inventiva. Portanto, o desamparo, mais do que uma condição humana existencial que nos empobrece, nos remete a imperiosidade da vida relacional coletiva, enfatizando que, a cultura/sociedade nem sempre está em posição antagônica a fluidez da vida. Nessa perspectiva, o psicanalista brasileiro Jurandir Freire Costa (2000) tem uma importante publicação sobre o tema.

2 A discussão sobre se o uso compulsivo de substâncias é ou evita sintomas, na psicanálise se expande em posições interessantes. Nesse texto, o foco não é esse, mas sustentamos que, o uso compulsivo de drogas, pode ser considerado sintoma no sentido amplo, até uma espécie de "sintoma do sintoma", no sentido de ter a função de evitar, mascarar, ou obscurecer dores e possibilidade de elaborá-las. Vide discussão sobre isso em Alberti, Inem, \& Corpas-Rangel (2003).

\section{Referências}

Alberti, S., Inem, C. L. \& Corpas-Rangel, F. (2003). Fenômeno, estrutura, sintoma e clínica: a droga. Revista Latino-americana de Psicopatologia Fundamental, 6(3), 11-29. Recuperado de https://www.redalyc.org/articulo.oa?id=2330/233018065002

Almeida, R. A. (2013). Fatores associados ao abandono do tratamento por usuários do centro de atenção psicossocial álcool e outras drogas em João Pessoa. Dissertação de Mestrado, Universidade Federal da Paraíba, João Pessoa, PB.

Almodóvar, P. (2011). La piel que habito. Direção: Pedro Almodóvar. Roteiro: Pedro Almodóvar \& Thierry Jonquet. 117 min. Warner Bros.

Butler, J. (2017). A vida psíquica do poder: teorias da sujeição. (Rogério Betonni, trad.). Autêntica. (Original publicado em 1997)

Costa, J. F (2000). O mito psicanalítico do desamparo. Agora (Rio de Janeiro), 3(1), 25-46.

Deleuze, G. (2018). Cartas e outros textos - Gilles Deleuze. N-1 Edições.

Deleuze, G. \& Guattari, F. (1976). O Anti-Édipo: capitalismo e esquizofrenia (Georges Lamaziere, trad.). Imago. (Original publicado em 1972)

Deleuze, G. \& Guattari, F. (1992). O que é a filosofia? (Bento Prado \& Alberto Alonso Muñoz, trads.). Editora 34. (Original publicado em 1991)

Farina, D. L. (2015). Entre Gilles Deleuze e Fernando Pessoa: modernidade e sensação. Monografia de Graduação, Universidade Federal do Rio Grande do Sul, Porto Alegre, RS. 
Ferenczi, S. (1992). A criança mal acolhida e sua pulsão de morte. In Obras completas de Sándor Ferenczi (vol. 4, pp. 47-51). Martins Fontes. (Original publicado em 1929)

Fernandes, S. S., Marcos, C. B., Kaszubowski, E., \& Goulart, L. S. (2017). Evasão do tratamento da dependência de drogas: prevalência e fatores associados identificados a partir de um trabalho de Busca Ativa. Cad. Saúde Colet. (Rio de Janeiro), 25(2), 131-137. http://www.scielo. $\mathrm{br} / \mathrm{pdf} / \mathrm{cadsc} / \mathrm{v} 25 \mathrm{n} 2 / 1414-462 \mathrm{X}$-cadsc-1414-462X201700020268.pdf

Foucault, M. (1984). História da sexualidade II: o uso dos prazeres (Maria Thereza C. Albuquerque, trad.). Graal. (Original publicado em 1984)

Foucault, M. (1997). Subjetividade e verdade (1980-1981). In Resumos dos Cursos do Collège de France (1970-1982) (pp. 107-115). Zahar.

Freud, S. (1976). Uma dificuldade no caminho da psicanálise. In Edição Standard Brasileira as Obras Completas de Sigmund Freud (vol. XVII, pp. 171-179). (Imago. (Original publicado em 1917)

Freud, S. (1992). Inhibition, symptôme et angoisse. In CEuvres complètes (vol. XVII, pp. 203-286). Direction scientifique Jean Laplanche. PUF. (Original publicado em 1926)

Galindo, D., Moura, M. M., \& Méllo, R. P. (2017). Comunidades terapêuticas para pessoas que fazem uso de drogas: uma política de confinamento. Barbarói (Santa Cruz do Sul), 50, 226-244.

Giacóia, O. (2002). A era das incertezas. Diário do Nordeste, Fortaleza, 02 nov., Recuperado de http://diariodonordeste.verdesmares.com.br/cadernos/caderno-3/a-era-das-incertezas-1.272946

Lacan, J. (1985). O Seminário, livro 2: O eu na teoria de Freud na técnica da psicanálise (1954-1955) (Marie-Christine Laznik Penot, Trad.). Jorge Zahar. (Original publicado em 1978)

Lima, E. M. F. A. \& Pelbart, P. P. (2007). Arte, clínica e loucura: um território em mutação. História, Ciências, Saúde, 14(3), 709-735. Recuperado de http://www.scielo.br/pdf/hcsm/ v14n3/02.pdf

Maia, A. B., Medeiros, C. P., \& Fontes F. (2012). O conceito de sintoma na psicanálise: uma introdução. Estilos da Clínica, 17 (1), 44-61. Recuperado de http://pepsic.bvsalud.org/pdf/estic/v17n 1/v17n1a04.pdf

Méllo, R. P. (2016). As drogas cotidianas em tempos de sobrevivência. In L. Vieira, L. Rios, \& T. Queiroz (Orgs.), A problemática das drogas: contextos e dispositivos de enfrentamento (pp. 20-52). EDUFPE.

Méllo, R. P. (2018). Cuidar? De quem? De quê? A (à) ética que nos conduz. Appris.

Méllo, R. P. (2019). Processos formativos em itinerâncias e grupalidades, tranversalizadas pelo cuidado de si e do outro. In B. Medrado \& M. M. Teti (Org.), Problemas, controvérsias e desafios atuais em psicologia social (pp. 226-240). ABRAPSO.

Miguel, M. (2015). Guerrilha e resistência em Cévennes. A cartografia de Fernand Deligny e a busca por novas semióticas deleuzo-guattarianas. Revista Trágica: estudos de filosofia da imanência, 8(1), 57-71. Recuperado de http://tragica.org/artigos/v8n 1/miguel.pdf

Nietzsche, F. (2008). A vontade de poder. Contraponto. (Original publicado em 1906)

Palombini, A. L. (2007). Vertigens de uma psicanálise a céu aberto: a cidade. Contribuições do acompanhamento terapêutico à clínica na reforma psiquiátrica. Tese de Doutorado, Universidade do Estado do Rio de Janeiro, Rio de Janeiro, RJ. 
Pelbart, P. P. (2013). O teatro da loucura. Poliética, 1(1), 119-129. Recuperado de https:// revistas.pucsp.br/index.php/PoliEtica/article/view/15206/11344

Pessoa, F. (1988). O banqueiro anarquista e outras prosas. Cultrix. (Original publicado em 1922) Preciado, P. B. La izquierda bajo la piel - um prólogo para Suely Rolnik. In S. Rolnik. Esferas da insurreição - Notas para uma vida não cafetinada. (pp. 11-21). N-1 Edições.

Rocha, Z. (1999). Desamparo e metapsicologia: para situar o conceito de desamparo no contexto da metapsicologia freudiana. Síntese, 26(86), 331-346.

Rolnik, S. (2018). Esferas da insurreição - Notas para uma vida não cafetinada. N-1 Edições.

Santos, L. F. (1997). Pensar o desejo: Freud, Girard e Deleuze. Instituto de Educação e Psicologia, Universidade do Minho.

Schopenhauer, A (2014). A dores do mundo: o amor, a morte, a arte, a moral, a religião, a política, o homem e a sociedade (José S. Oliveira, trad.). EDIPRO. (Original publicado em 1850)

Vieira, M. R. J. \& Cintra, E. M. U. (2016). O trabalho criativo: perda, luto e metáfora. Gerais: Revista Interinstitucional de Psicologia, 9(1), 50-66. Recuperado de http://pepsic.bvsalud.org/ pdf/gerais/v9n1/v9n1a05.pdf

Virilio, P. (1993). O Espaço crítico (Paulo Roberto Pires, trad.). Editora 34. (Original publicado em 1984)

Winnicott, D. W. (1975). O brincar e a realidade. Imago. (Original publicado em 1971)

\section{RICARDO PIMENTEL MÉLLO}

https://orcid.org/0000-0002-9990-3837

Doutorado em Psicologia (Psicologia Social) pela Pontifícia Universidade

Católica de São Paulo (2002). É professor associado do departamento de

Psicologia da UFC. Colaborador do Núcleo de Pesquisa e Estudos sobre

Práticas Discursivas e Produção de Sentidos (PUC/SP) e do Núcleo de

Estudos e Pesquisas sobre Drogas (UFC).

E-mail: ricardopmello@gmail.com

\begin{tabular}{|l|l|}
\hline Histórico & $\begin{array}{l}\text { Submissão: 27/06/2020 } \\
\text { Revisão: 02/12/2020 } \\
\text { Aceite: 02/12/2020 }\end{array}$ \\
\hline $\begin{array}{l}\text { Contribuição } \\
\text { dos autores }\end{array}$ & $\begin{array}{l}\text { Redação inicial e final do texto, além de padronização das normas de } \\
\text { acordo com a revista. }\end{array}$ \\
\hline Financiamento & Não se aplica. \\
\hline
\end{tabular}

